\title{
Impact of non-invasive follicular thyroid neoplasms with papillary-like nuclear features on risk of malignancy
}

\author{
Aldona Kowalska \\ Endocrinology Clinic, Holycross Cancer Centre, Kielce, Poland
}

Correspondence should be addressed

to A Kowalska

Email

aldonako@onkol.kielce.p

\section{Dear Editor,}

I read the paper by Bongiovanni et al. (1), entitled "Impact of non-invasive follicular thyroid neoplasms with papillary-like nuclear features (NIFTP) on risk of malignancy in patients undergoing lobectomy/ thyroidectomy for suspicious for malignancy or malignant fine-needle aspiration cytology findings: a systematic review and meta-analysis" with great interest.

This systematic review was undertaken to obtain more robust information about the true impact of NIFTP on the risk of malignancy (ROM) among patients who underwent surgery after fine-needle aspiration cytology (FNAC)-based diagnosis of suspicious for malignancy (Bethesda V) or malignant (Bethesda VI).

It is worth noting that all the studies included in this meta-analysis were published before August 2018, and all used the diagnostic criteria for NIFTP (i.e. encapsulation or clear demarcation; follicular growth pattern with $<1 \%$ papillae; no psammoma bodies; $<30 \%$ solid/trabecular/ insular growth pattern and a nuclear score of 2-3; absence of vascular or capsular invasion; absence of tumor necrosis; and low mitotic activity) proposed initially by Nikiforov in 2016 (2). Although several studies were published since, this initial NIFTP report suggests that the tumor has low malignant potential, and several cases with micrometastasis in regional lymph nodes and tumors that apparently meet the proposed diagnostic criteria for NIFTP have been reported. These studies show that the arbitrary cutoff of $<1 \%$ papillae misclassifies non-invasive classical papillary thyroid carcinomas with predominant follicular architecture as $\operatorname{NIFTP}(3,4,5)$.

In 2018, to avoid misdiagnosing papillary thyroid cancer as NIFTP, Nikiforov et al. proposed changes to the criteria for NIFTP qualification. The most significant difference was replacing the criterion 'less than 1\% papillae' with 'no well-formed papillae', and the introduction of the following secondary diagnostic criterion: 'lack of $B R A F$ V600E mutation or other high-risk mutations helpful, but not required for, NIFTP diagnosis' (6). This revision has a crucial impact because it reduces the number of NIFTP diagnoses. In our study, we found that 23 out of 1117 patients with thyroid cancer were diagnosed with NIFTP according to the 2016 criteria. However, the revised criteria from 2018 resulted in only 13/1117 diagnoses of NIFTP.

It appears reasonable to point out, therefore, that a limitation of the above meta-analysis is that it comprises studies based on obsolete diagnostic criteria, which affects value of the results. Further studies that evaluate the impact of NIFTP on ROM should be conducted based on the revised criteria. I expect that the results will show that impact of NIFTP on ROM will be less marked than suggested by this meta-analysis.

\section{Declaration of interest}

The author declares that there is no conflict of interest that could be perceived as prejudicing the impartiality of the research reported.

\section{Funding}

This research did not receive any specific grant from any funding agency in the public, commercial or not-for-profit sector.

\section{References}

1 Bongiovanni M, Faquin WC, Giovanella L, Durante C, Kopp P \& Trimboli P Impact of non-invasive follicular thyroidneoplasms with papillary-like nuclear features (NIFTP) on risk of malignancy in patients undergoing lobectomy/thyroidectomy for suspicious for (c) 2019 European Society of Endocrinology Printed in Great Britain
Published by Bioscientifica Ltd. 
malignancy or malignant fine-needle aspiration cytology findings: a systematic review and meta-analysis. European Journal of Endocrinology 2019181 389-396. (https://doi.org/10.1530/EJE-19-0223)

2 Nikiforov YE, Seethala RR, Tallini G, Baloch ZW, Basolo F, Thompson LDR, Barletta JA, Wenig BM, Ghuzlan AA, Kakudo K, et al Nomenclature revision for encapsulated follicular variant of papillary thyroid carcinoma: a paradigm shift to reduce overtreatment of indolent tumors. JAMA Oncology 20162 1023-1029. (https://doi. org/10.1001/jamaoncol.2016.0386)

3 Lee SE, Hwang TS, Choi YL, Kim WY, Han HS, Lim SD, Kim WS, Yoo YB \& Kim SK Molecular profiling of papillary thyroid carcinoma in Korea with a high prevalence of BRAF(V600E) mutation. Thyroid 201727 802-810. (https://doi.org/10.1089/thy.2016.0547)

4 Cho U, Mete O, Kim MH, Bae JS \& Jung CK Molecular correlates and rate of lymph node metastasis of non-invasive follicular thyroid neoplasm with papillary-like nuclear features and invasive follicular variant papillary thyroid carcinoma: the impact of rigid criteria to distinguish non-invasive follicular thyroid neoplasm with papillarylike nuclear features. Modern Pathology 201730 810-825. (https://doi. org/10.1038/modpathol.2017.9)

5 Parente DN, Kluijfhout WP, Bongers PJ, Verzijl R, Devon KM, Rotstein LE, Goldstein DP, Asa SL, Mete O \& Pasternak JD Clinical safety of renaming encapsulated follicular variant of papillary thyroid carcinoma: is NIFTP truly benign? World Journal of Surgery 201842 321-326. (https://doi.org/10.1007/s00268-017-4182-5)

6 Nikiforov YE, Baloch ZW, Hodak SP, Giordano TJ, Lloyd RV, Seethala RR \& Wenig BM Change in diagnostic criteria for noninvasive follicular thyroid neoplasm with papillarylike nuclear features. JAMA Oncology 20184 1125-1126. (https://doi.org/10.1001/ jamaoncol.2018.1446)

Received 29 August 2019

Accepted 26 September 2019 